\title{
Fire risk reduction on the margins of an urbanizing world
}

Walls, Richard; Twigg, John; Spinardi, Graham; Jordan, Steve; Hirst, Laura; Gibson, Lesley;

\author{
Cooper-Knock, Sarah-Jane; Rush, David; Bankoff, Greg
}

\section{Structured Abstract:}

- Purpose:

Globally, over $95 \%$ of fire related deaths and injuries occur in low- and middle-income countries. Within informal settlements, the risk of fire resulting in injury or death is particularly high. This paper examines fire risks in informal settlements in New Delhi and Cape Town, and tented informal settlements in Lebanon.

\section{- Approach:}

Our analysis draws on primary sources, secondary literature, statistical data and qualitative interviews.

\section{- $\quad$ Findings:}

The distribution of fire risk across urban societies is a fundamentally political issue. Residential fire risk can be tackled by accessible, affordable, safety-compliant housing. That said, important interim measures can be taken to mitigate fire risk. Some of the risks requiring attention are similar across our case studies, driven by high population densities; flammable housing materials; unreliable or inaccessible access to safe power sources; and in the case of Cape Town and New Delhi particularly - the inability of fire services to reach sites of fire. However, these common risks are embedded in distinct social, economic and political contexts that must be placed at the centre of any intervention. Interventions must also be aware that the risk of fire is not spread evenly within informal settlements, intersecting as it does with factors like gender, age, health and disability.

\section{- Originality:}

Informal settlement fires have been under-studied to date. The studies that do exist tend to operate within disciplinary silos. This paper represents an important interdisciplinary approach to fire within informal settlements, which grounds technical data, modelling and experiments in political, social and economic realities.

KEYWORDS: Urban fire, risk reduction, case studies, New Delhi, Cape Town, Lebanon, Refugee

\section{INTRODUCTION:}

More than 150,000 people die from fires or burn-related injuries every year. Over $95 \%$ of fire deaths and burn injuries are in low- and middle-income countries (LMICs)(WHO, 2018). In informal settlements, the risk of fire resulting in trauma, injury or death is particularly high. But too little is known about the triggers, incidence and impact of such fires. 
Urban growth is one of the 21st century's most transformative trends posing massive sustainability challenges in terms of housing, infrastructure and basic services (UN Habitat, 2016). This growth is predominantly in developing countries, where urban areas grow by an estimated 70 million people each year (UN Habitat, 2015a). Low income countries have seen a 300\% increase in urban areas and a $176 \%$ increase in population in the past 40 years (Paresi et al., 2016).

The distribution of fire risk across urban societies is a fundamentally political issue. Here, we focus on the risks to residents within informal settlements and refugee camps; two spaces that testify to the fact that risk reflects structural patterns of oppression and marginalisation ${ }^{1}$. We introduce these spaces below before exploring three case studies that emphasise the range of factors that shape fire risk in informal settlements in New Delhi (India), Cape Town (South Africa), and in tented informal settlements (refugee camps) across Lebanon.

\section{Informal Settlements}

Affordable and accessible urban housing has not kept pace with rising global population growth (Gunter and Massey, 2017). Consequently, people have been forced to live in low quality formal housing or within informal settlements. Both forms of housing expose people to increased fire risk, but we focus here on residential informal settlements.

We use the term 'informal settlement' to refer to informal dwellings in collective form, incorporating all settlements that did not have formal state permission when constructed. We focus on informal settlements occupied by lower socio-economic groups. To call a settlement 'informal' does not mean that it is illegitimate or temporary. Moreover, just because such settlements were not planned or permitted by the state does not mean they were unplanned per se: informal settlements can be designed and shaped by residents in a variety of ways.

The proportion of urban residents living within these informal settlements has declined in recent years, however the absolute number of their residents has grown by 213 million since 1990 (UN Habitat, 2015a). Fires within informal settlements are frequent and spread with devastating speed. In February 2011, for example, a fire left 10,000 homeless in Bahay Toro, Philippines, in just three hours (Twigg et al., 2017). Across the globe, English-language media online reported that 20,000 homes were destroyed by fire in 2018 alone ${ }^{2}$. If we conservatively assume that an average of four people live in each household approximately 86,000 people have been displaced (Gibson et al., 2019).

\footnotetext{
${ }^{1}$ To say that people are marginalised, in this context, is to speak of a relationship of power. When we talk of marginality we are not necessarily suggesting that people are completely peripheral and, as such, society could exist without them. Far from it. As Veena Das and Deborah Poole (2004)remind us, what is marginalised is often also that upon which society rests.

${ }^{2}$ https://www.iris-fire.com/downloads/media-reports-of-is-fires/, - Accessed [12/03/2019]
} 
$\underline{\text { Camps }}$

The definition of a refugee camp or camp for internally displaced persons (IDPs) is complicated by the variety of camps that exist. Camps differ greatly in terms of size, infrastructure, building type and governance. Some are established and maintained by external organisations, like the UNHCR. Others are 'self-settled camps' or 'autonomous settlements', which are often more integrated in surrounding society (Schmidt, 2003). The size, shape and governance of a camp can also shift markedly over time (Turner, 2006), with the inflow of people producing population sizes and densities that can surpass that of local cities. The Zaatari refugee camp, for example, is the 'fourth largest concentration of people in Jordan' (Crisp, 2015). To call it a city, however, is to overlook the lack of citizenship that characterises the daily lives of refugees (Crisp, 2015). These refugees are living in urban conditions but not within cities.

Many forcibly displaced people also live outside camp structures and may form part of the marginalised urban populations mentioned above. An estimated $60 \%$ of the refugee population and $80 \%$ of the IDP population live in urban areas worldwide (UNHCR, 2011). At the end of 2015, more than 6.6million refugees had spent over five years in exile ${ }^{3}$. Some have spent far long - some Palestinian refugee camps and Eritrean refugee camps in Sudan were founded in 1948 and 1968, respectively. Given the numbers of people living in camps and the length of their encampment, fire safety in these settlements is clearly crucial. To date, however, it has been largely overlooked.

Our case studies highlight the political, social and economic context in which fire risk is experienced.

\section{Case Studies:}

\section{New Delhi}

Urban fire is a hidden problem in India, largely unseen and underreported despite the devastation it causes. Officially, police statistics reported 17,700 deaths by 'accidental fire' (excluding forest fire) in 2015 (National Crime Records Bureau, 2016). However, a 2001 study suggests this figure might be six times higher, (Jagnoor et al., 2009, Sanghavi, Bhalla and Das, 2009). ${ }^{4}$ This makes fire second, behind traffic accidents, as the main cause of death by ‘unnatural causes' (National Crime Records Bureau, 2016).

New Delhi is the second most densely populated city in India after Mumbai. UN projections suggest that it will become the most populous city in the world by 2028 (UN, 2018). Population density varies greatly from 4,057 persons $/ \mathrm{km}^{2}$ in New Delhi district to 36,155 persons $/ \mathrm{km}^{2}$ in the North district (Delhi Fire Service (DFS), 2017).

\footnotetext{
${ }^{3}$ https://blogs.worldbank.org/dev4peace/how-many-years-do-refugees-stay-exile

${ }^{4}$ This number was extrapolated from hospital registry data for urban areas and a survey of causes of death in rural populations.
} 
Official statistics reported 318 deaths and 1,767 people injured by fire in 2017-2018 (Delhi Fire Service (DFS), 2017). These figure are highly likely to be underestimates, given that the underrepresentation of data in urban areas (Sanghavi et al., 2009). Anecdotal evidence suggests that large-scale urban fires occurring in the "colonies" (districts) of the outer suburbs are not fully recorded in official statistics (Interview: Community Spokesperson 1, North West Delhi 27/7/18) with potentially thousands of incidences being unrecorded (Satapathy and Walia, 2007). Official statistics are collated by the Police Department who are required to attend all callouts of the Delhi Fire Service (DFS).

Inequality fundamentally shapes the distribution of fire risk in New Delhi (Bankoff et al., 2012). Fire regulations (namely the National Building Code, the Delhi Fire Prevention and Fire Safety Act 1986, and provisions of the Delhi Fire Service Act 2007) are broadly followed in the relatively affluent centre with its government buildings, embassies and upmarket residences; in the formal commercial and retail sectors; and in the middle-to-upper class suburbs. Buildings of five stories or over also require a No Objection Certificate (NOC) from the DFS before occupancy. Of course, fires do occur in these more affluent spaces and not all landlords adhere to fire regulations. The violation of existing safety regulations in this building prompted the passing of the Delhi Fire Prevention of Fire Safety Act after three lives were lost in a high-rise office building fire in $1986^{5}$ (Interview: Senior DFS Officer 1, New Delhi 13/4/18). Overall, however, economic resources are sufficient here for people to fulfil building regulations. These are sufficiently policed - by occupants and the state - to enforce compliance. Only traffic limits fire service access to such properties.

Elsewhere, construction materials, poor infrastructure, population density, and limited access combine to heighten fire risk. Numerous informal settlement forms exist on Delhi's urban margins, spanning the spectrum of formality and legality. As Bhan (2009:131) highlights, only $23.7 \%$ of Delhi residents abide in 'planned colonies that met all conditions of legality' when they were established'. The term 'unauthorised colonies' tends to refer to more affluent but illegal housing; the poorer equivalents of these dwellings are referred to as 'JJ Clusters' (Ibid). Those living in 'slum-designated areas' may be in a similar economic position to those in JJ Clusters but their areas were authorised through the 1956 Slum Areas Act (Ibid.).

Unsurprisingly, given their similar architectural and socio-economic profile, there are similar fire risks in areas designated as 'slums' and 'JJ Clusters', due to population density, flammability of building materials and reliance on open flames. Traffic also poses a challenge for fire services. The average speed for engines used to be 
25-30 km/h but now can be down to $5 \mathrm{~km} / \mathrm{h}$ during peak traffic times (Interview: Senior DFS Officer 1, New Delhi 13/4/18). This means regular delays of 40-45 minutes for engines to reach a fire, with one informant reporting that she had to wait three hours ${ }^{6}$ (Interview: Community Spokesperson 1, North West Delhi 27/7/18). Finding the precise location of fires is very difficult due to the absence of formal postal addresses. One station officer estimates that, at his station, engines are not able to find the fire in up to $30 \%$ of callouts (Interview: Station Officer 4, North West Delhi 11/4/18). Even when an engine reaches its destination, it may not be able to approach the blaze due to the narrowness of the thoroughfares (see Figure 1). In these cases, multiple 100-metre hoses are linked together, reaching 500 metres or more (Interview: Station Officer 3, South Delhi 12/4/18). Most areas in Delhi do not have fire hydrants; those that do exist may have low pressure or limited supply. Community involvement in fire-fighting - in terms of summoning fire services or tackling fires directly - has been under-researched in New Delhi.

${ }^{6}$ The time from fire detection to the call being raised to the fire service in this particular case is unknown. 


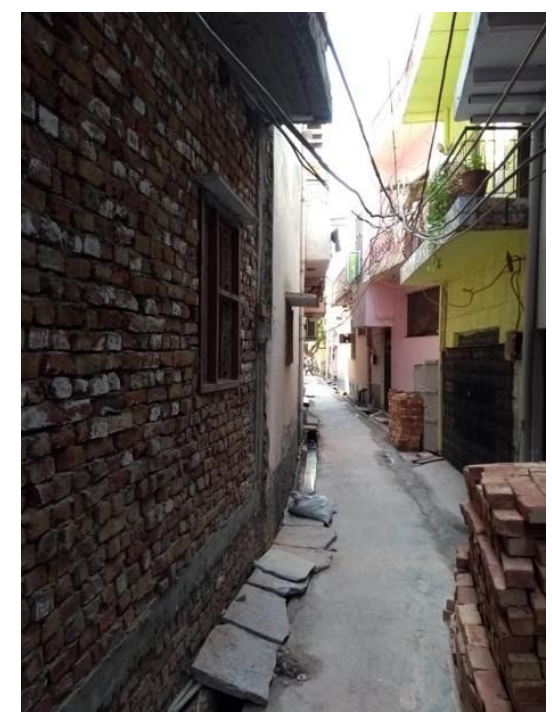

Figure SEQ Figure 1" ARABIC 1: Harrow lane in Shabbad Muhamdar [left] and informal housing = Railway Colong (right!

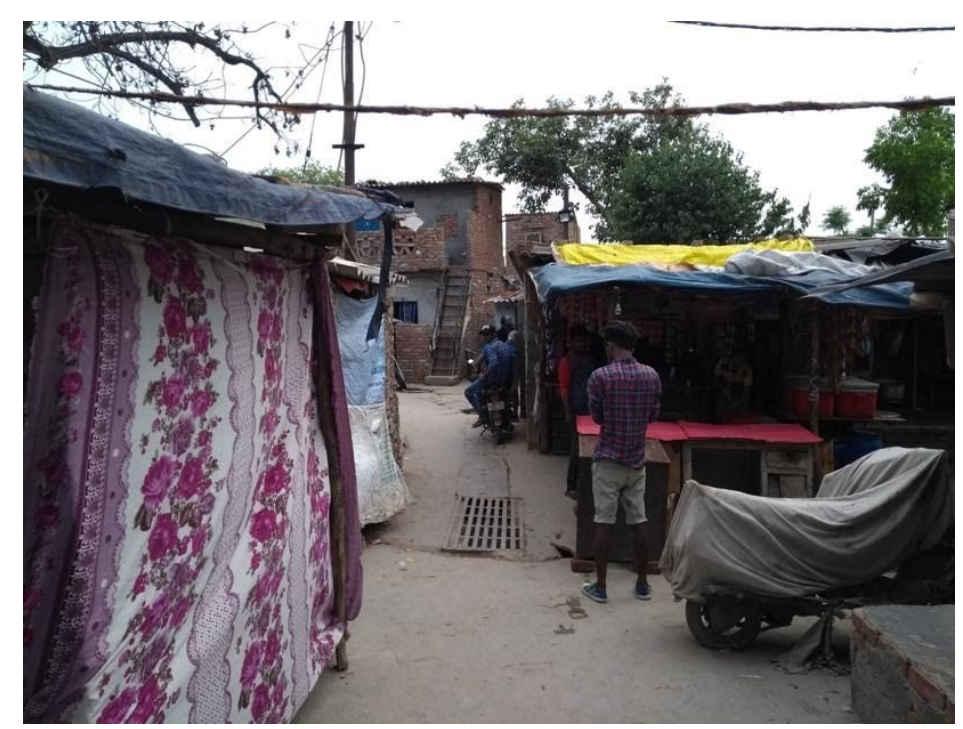

Fire services have attempted to tailor their equipment to better tackle informal settlement fires, such as smaller, four-wheeled vehicles and motorcycles equipped with hydraulic pumps or foam apparatuses. For water, the DFS relies on a fleet of tankers from 3,000 L capacity for narrower thoroughfares to giant $12,000 \mathrm{~L}$ tankers. Larger fires need a fleet of tankers continuously circulating between the fire and a water source and which in many cases, may be up to $12 \mathrm{~km}$ away. Tanker and take up to 1.5-2 hours to refill and return to the fire (Interview: Senior DFS Officer 1, New Delhi 13/4/18). Firefighting equipment, pumps, hoses, breathing apparatuses and flame-retardant clothing is generally regarded as adequate and in good working order. However, firefighters seldom want to don heavy safety gear, modelled on western designs, in summer temperatures that regularly exceed $35^{\circ} \mathrm{C}$, and where most buildings' entrances and corridors are extremely narrow (Interview: Station Officer 2, South East Delhi 25/7/18). This increases firefighter fatalities and encourages external rather than internal 
firefighting, despite senior officer's claims to the contrary (Interview: Station Officer 4, North West Delhi 11/4/18; Interview :Senior DFS Officer 1, New Delhi 13/4/18).

Gender intersects with the political and economic factors, heightening fire risk. Across India, nearly two-thirds (106,000 out of 163,000 in 2001) of all fire deaths are female, mostly between 15 and 34 years of age. This proportion is higher in urban areas. Whilst specific data on Delhi is lacking, there is no reason to believe that fire risk in the city is not highly gendered. Official statistics do not provide insight into the causes of these fire deaths, but qualitative research suggests that they may, in part, be attributable to the gendered social and economic roles of women who take primary responsibility for domestic cooking. Cooking with open flames or poor electricity connections can be hazardous. In poorer homes, cooking is done outside over an open fire to minimise fire risk (Interview: Community Spokesperson 1, North West Delhi 27/7/18). Additionally, there is a high prevalence of females within industrial spaces - such as textile factories - that flout fire regulations ${ }^{7}$, and local studies suggest that over a third of fire-related deaths may be attributed to suicide-by-self-immolation or domestic violence in response to a bride's proposed dowry (Kapur 2002, Sanghavi, Bhalla and Das, 2009).

Arson, be it for insurance fraud or for land clearance, is another trigger for fires in Delhi. For instance, a whole "colony" of informal structures in Bawana in North West Delhi was deliberately set alight with locals reporting that the fire brigade unfortunately only arriving after the entire settlement had burnt to the ground, the implication being that the delay was intentional (Interview: Community Spokesperson 1, North West Delhi $27 / 7 / 18)$

Fire ignition and fire spread in Delhi are seasonal. Stations receive fewer callouts in winter - on average one or two each day - than in summer (April to July) which may be as many as six calls every 24 hours with the fire risk exacerbated by high temperatures (Interview: Station Officer 2, South East Delhi 25/7/18). Fires are also more frequent during the monsoons because rainwater causes appliances to short-circuit. Sparks can be generated at any time of the year as the intermittent power supply to many areas of the city causes power surges (Interview: Station Officer 1, South Delhi 26/7/18). In turn, regular 'brownouts' (electricity reductions) mean that many local residents use candles for illumination (Interview: Community Spokesperson 1, North West Delhi 27/7/18). Festivals add to the seasonal rhythms of fire. During Diwali, for example, private and public spaces are illuminated by lights or oil lamps called diyas and fireworks are launched. The convergence of so many naked flames, crowds and festivities results in the DFS receiving as many as $200+$ callouts between $4 \mathrm{pm}$ and 1am on that single night (Interview: Senior DFS Officer 1, New Delhi 13/4/18).

\footnotetext{
${ }^{7}$ For instance https://www.aljazeera.com/news/2016/11/fire-kills-factory-workers-india-sahibabad-161111072912321.html
} 


\section{Cape Town}

South Africa is the world's most unequal country. In 2011, approximately 1.66 million households resided in informal residential areas, from a total population of 51.8 million. ${ }^{8}$ Estimates suggest that between $18 \%$ and $33 \%$ of the population live in 'backyard dwellings' (informal structures erected on formal housing sites) (Pharoah, 2009).

The Fire Protection Association of South Africa (FPASA) compiles data on fire from brigades across the country but not all brigades provide complete reporting (FPASA, 2018). Consequently, the data typically underestimates incidence data. In 2016, FPASA recorded 41,873 fire callouts nationally (approximately 115 fires per day). Between 2003-2016, the number of fires increased between 1.5-1.7\% per annum with the number of fatalities rising between 5-10\% per annum (FPASA, 2018). This only includes fatalities recorded by fire services at the site of the fire. Injuries that result in later fatalities are not included. Notably, 2011 mortuary data reported that 2,243 people died from 'exposure to smoke, fire and flames' - 8.0\% of all 'accidental injuries' (StatsSA, 2014) a figure $447 \%$ higher than the FPASA statistics.

The absolute numbers of fires within formal and informal dwellings are similar (Figure 2) but with an estimated $18 \%$ of the population living in informal settlements, informal settlement residents are 4.8 times more likely to be affected by fire. The burden of fire disasters is often borne by the poor.

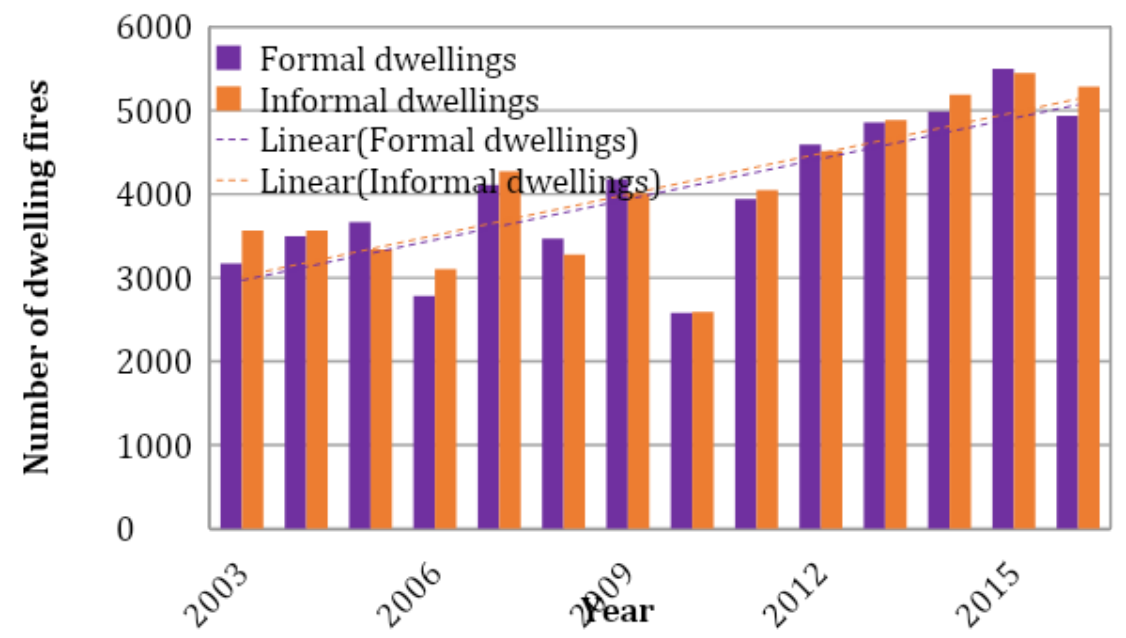

Figure 2: Total number of dwelling fires recorded by fire services in SA for formal and informal dwellings

Cape Town, home to four million people, is the world's fifth most unequal city and still bears the marks of apartheid segregation. Unemployment remains approximately $27 \%$ across the country and whilst the

\footnotetext{
${ }^{8}$ https://data.worldbank.org/indicator/SI.POV.GINI?locations=ZA - accessed 5/9/18
} 
government has delivered housing since 1994, an estimated backlog of 350,000 housing units remains (StatsSA, 2018). Much of the housing that has been delivered has reinforced the spatial marginalisation of economically deprived citizens, and has often been of mixed quality. The shortage and unsuitability of housing stock has meant that the number of people living within informal settlements and backyard dwellings continues to grow (Turok and Borel-Saladin, 2016). Whilst these settlements are not authorised by the government, their layout may be informally planned and locally governed. Some settlements have clear roads, walkways and gaps between homes, while others are very densely populated with narrow passages (Figure 3).

a)

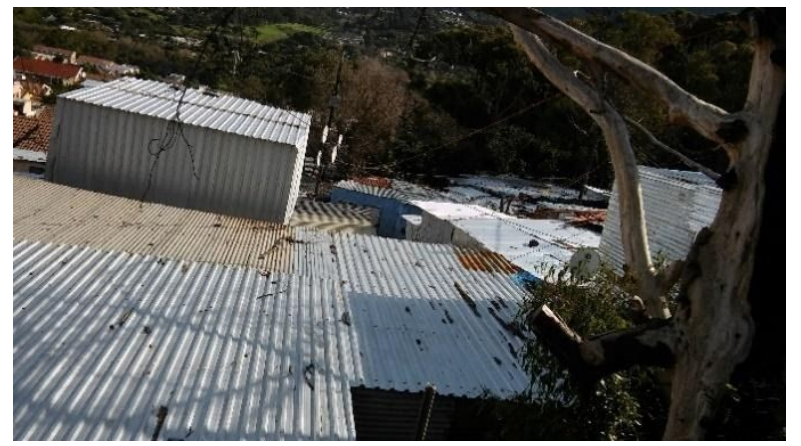

c)

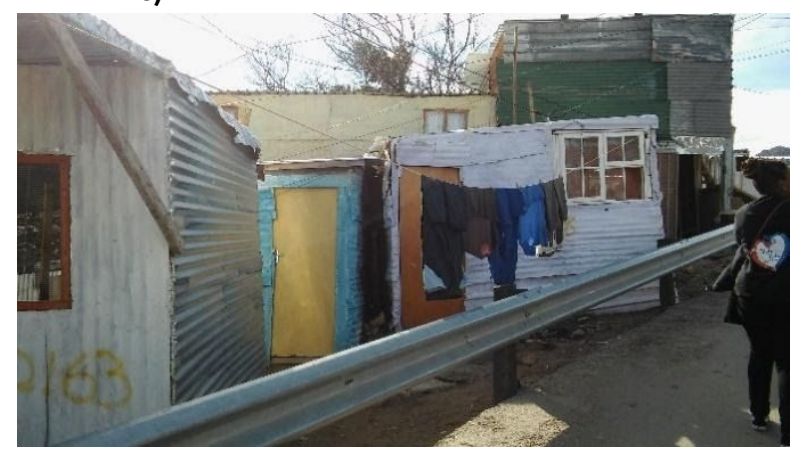

b)

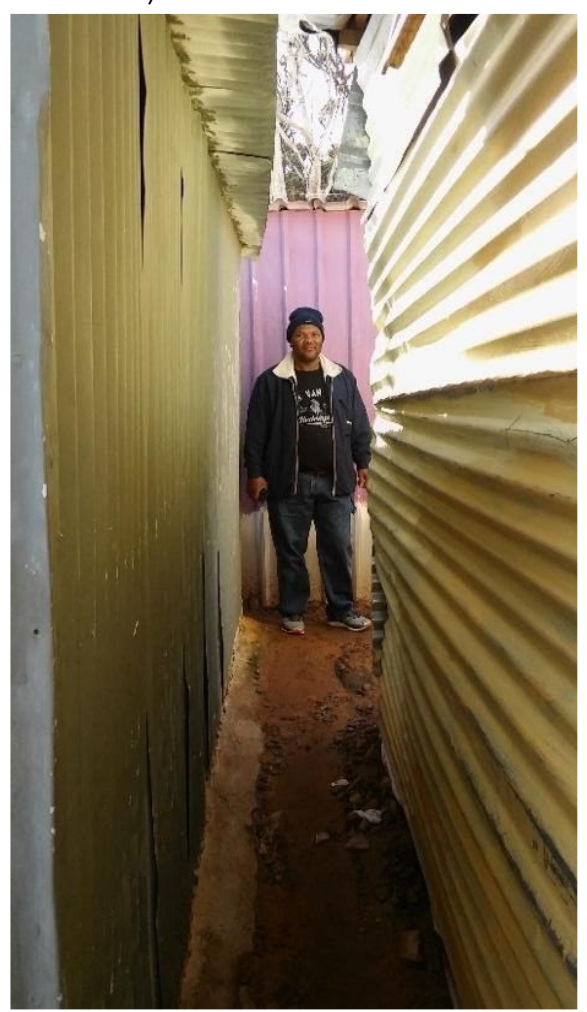

Figure 3: Imizamo Yethu informal settlement in Cape Town showing: a) close proximity of homes with roof structures possibly covering multiple households; b) narrow gaps between dwellings; and c) variety of building materials used in construction 


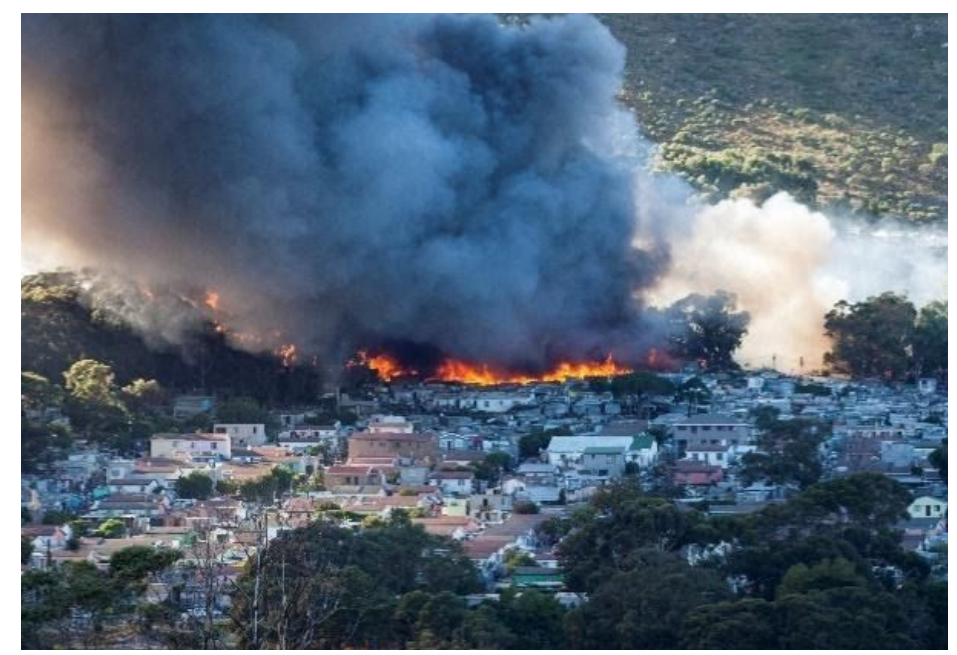

Figure 4: Fire spread through Imizamo Yethu in 2017 (used permission of Ryan Heydenrych, Vulcan Wildfire Services)

Fire risk is extremely high within informal settlements. As many as 10,000 people can be left homeless in a single fire (Pluke, 2017). In 2017, for example, a fire in Imizamo Yethu (Figure 4), left 2194 homes destroyed, despite the efforts of 176 firefighters (Kahanji et al., 2019). The disaster management and recovery from this incident cost the municipality over R100m (\$7m) (Pluke, 2017); approximately the cost of 650 low-cost homes.

Fire incident statistics collected by the City of Cape Town showed that between 2009 and 2015 the number of informal settlement fires doubled from just over 150 to over 320 fires per year. On average the fire service will be called out to an informal settlement fire once a day, and every week a fire will affect more than 20 dwellings. A spatial distribution analysis of fire incidents ${ }^{9}$ (Figure 5) reveals that some reveals that some settlements are prone to many fire incidents and in which many structures are destroyed, highlighting areas within the city at highest fire risk.

${ }^{9}$ Data is gathered from City of Cape Town, Fire incidence data, (2018). Available at: https://web1.capetown.gov.za/web1/opendataportal/DatasetDetail?DatasetName=Fire\%20incidence [Accessed 9 July 2018 ]. 
a)

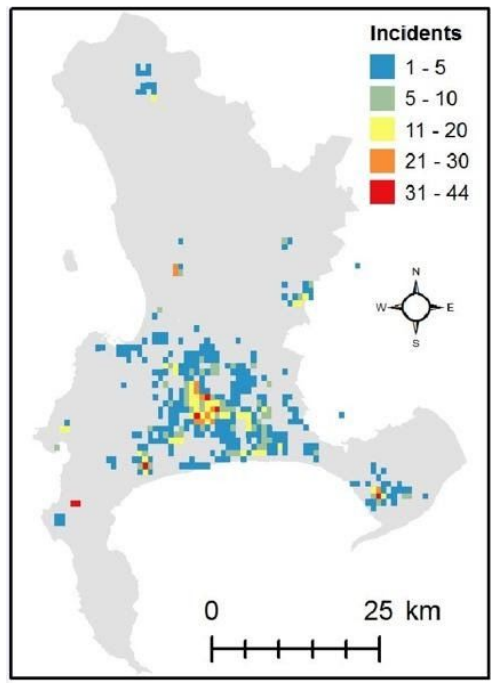

b)

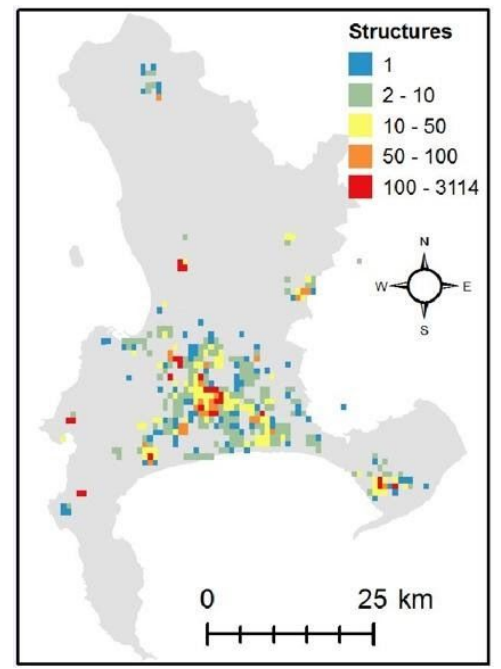

Figure 5: City of Cape Town fire incidence data for seven years from 2009 to 2015 showing; a) number of informal settlement fire incidences; and b) total number of structures destroyed in this seven year period.

The points of ignition within Cape Town's informal settlements are varied and under-reported, as in our other case studies. Electrification of dwellings is typically viewed as a method of improving fire safety, as inhabitants could stop using open fires or paraffin stoves. However, even when provided with metered electricity $67 \%$ of inhabitants may still employ "energy stacking" where they use both electric and non-electric (typically paraffin) energy sources due to the higher cost of electricity (Francioli, 2018).

Smoke and fire detectors provide a potential risk reduction solution. However, certain devices, for instance those relying on rate-of-temperature-rise, will not activate in smouldering fires (Walls et al., 2017). A smouldering fire is a low temperature fire with no visible flames (Quintiere, 2016). In the Wallacedene TRA settlement, a recent longitudinal study investigated the rollout of 1,400 photoelectric smoke alarm devices (Zweig et al., 2018). Although interpretation of the trial was complicated by the contemporaneous installation of electricity, anecdotal evidence indicated that some lives were saved due to early warning. However, further refinements to the devices are required to reduce the amount of false alarms, and make them suited to the realities of everyday life.

Another intervention in Cape Town is the application of intumescent paints, which expand upon heating and provide an insulating barrier. However, their effectiveness may be hampered by cost, durability and performance in fire (Krishnamoorthy and Bailey, 2009). Recent, unpublished, informal settlement dwelling fire tests indicate that openings between walls and roofs significantly reduce the effectiveness of such paint, unless it is combined with improved firestopping. 
Finally, reblocking has been attempted as a means of remodelling informal settlements to create fire breaks and better access for the fire services (Sokupa, 2012). This process can be highly contentious, as it involves the relocation and reconstruction of some people's homes. Whilst some efforts have been successful, other reblocking exercises have been forced to cease due to local opposition.

\section{Lebanon}

In Lebanon, one million registered Syrian refugees make up over $20 \%$ of the population (UNHCR, 2016). Large refugee flows started in March 2011, when refugees fled the Syrian civil war. In December 2012, countries neighbouring Syria were hosting half a million refugees, and by April 2014, there were one million registered refugees in Lebanon alone (UNHCR, 2016). ${ }^{10}$ Lebanon also hosts a Palestinian refugee community of approximately 250,000 people (UNHCR, 2016).

More than $70 \%$ of refugees within Lebanon live in poverty (UNHCR, 2016), as a result of the economic toll of displacement and the declining levels of growth and investment in the country (Inter-Agency Coordination Lebanon et al., 2018). Consequently, many live in hazardous, inadequate and overcrowded shelters (Ibid). For political reasons, the Government of Lebanon restricts materials that can be provided to refugees and the creation of refugee camps (locally referred to as tented informal settlements) is banned, hampering the improvement of building conditions (Ibid).

Whilst local authorities and humanitarian agencies have collaborated to enhance services and infrastructure for refugees and host communities (UNHCR, 2016), fire safety has not been prioritised. There is a lack of fire safety expertise within humanitarian agencies, and national firefighting capacity and fire safety is low. Fire risk as an issue in refugee contexts in Lebanon has often 'fallen through the cracks' between sectors and agencies. Redressing this gap is no easy task: political and social relations between and within host and refugee communities, humanitarian agencies, fire responders and different levels of government must be understood and engaged with strategically, reflecting the fact that fire risk and fire risk reduction is as political as it is technical.

Many displaced Syrians and Palestinians live in the approximately 7,000 mapped tented informal settlements scattered across Lebanon (Kazerooni et al., 2016). Settlements range from 1 to 238 tents with over half of the settlements having four or fewer tents. Of the residential and non-residential buildings used for habitation, $25 \%$ and $48 \%$ respectively are deemed below the minimum physical humanitarian standards (Inter-Agency Coordination Lebanon et al., 2018). These substandard buildings (SSB) such as garages, apartments, 
and unfinished buildings usually lack windows or doors (Zelkowitz et al., 2017). Fire risk is high across all categories of residence (Ibid) but building a comprehensive picture across settlements is difficult given the inconsistencies in fire reporting between and within stakeholder groups. Lebanese Civil Defence data on fire incidence show that between January 2016 and November 2017, there were approximately 1,800 reported fires in residential and non-residential buildings, and approximately 300 reported fires in informal settlements (Inter-Agency Coordination Lebanon et al., 2018). Numerous fires, however, may not be reported directly to the Civil Defense but to other humanitarian agencies, or not at all. Anecdotal evidence suggests that these fires usually affect more than one home.

The number of injuries caused by these fires is high. UNHCR data show 120 displaced persons with severe burns during 2015, with children under 5 being half of those injured. However, this is likely to be the "tip of the iceberg" as UNHCR only has the capacity to treat severe life-threatening cases; many more injuries, like smoke inhalation, non-fatal burns, and psychological trauma may be treated elsewhere or remain untreated (Zelkowitz et al., 2017). The fire fatality rate for Lebanon in 2017 was 1.48 fatalities/100,000/year (UK was 0.55$)^{11}$. Fire fatalities in informal settlements are frequent, with 14 recorded deaths (12 children) between July and December 2017 (a rate of 11.2 fatalities/100,000/year) (Inter-Agency Coordination Lebanon et al., 2018). Refugees also face a loss of property to fire. The loss of documentation, in particular, can have stark consequences for refugees seeking socio-economic opportunities and assistance (Zelkowitz et al., 2017).

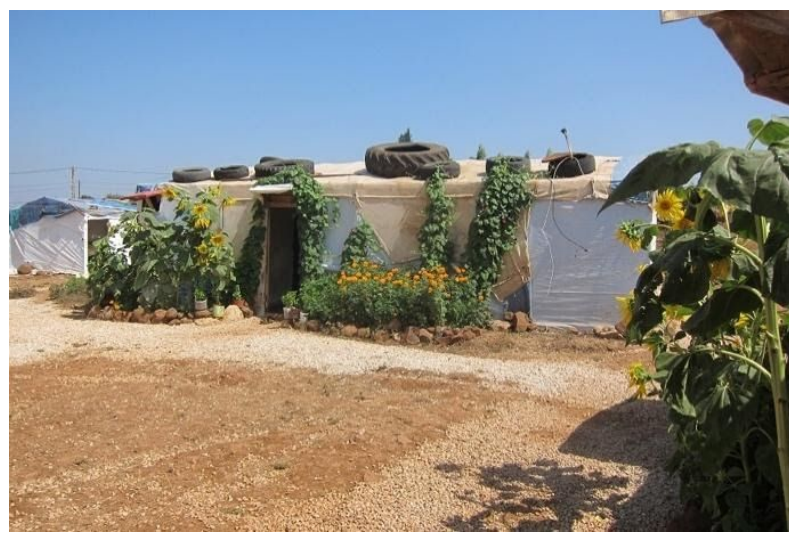

a)

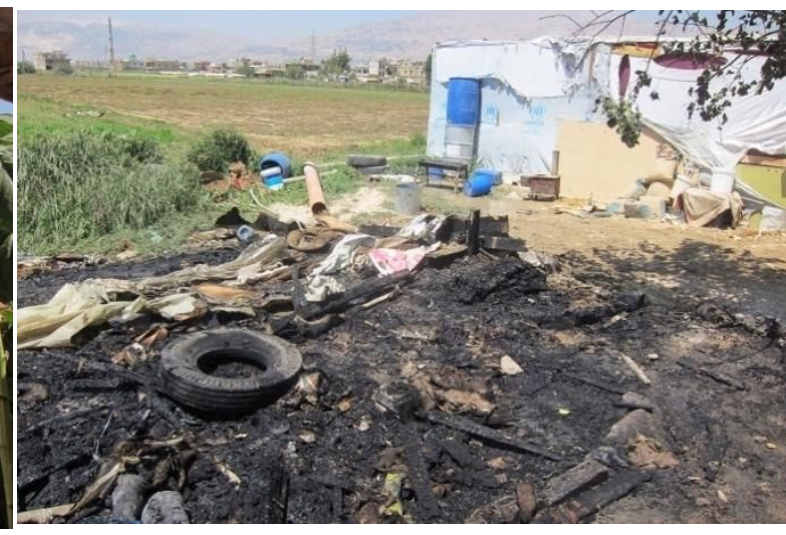

b)

Figure 6: a) Tents in an informal refugee settlement in the Akkar region, where tyres are used to keep tents secure but contribute to a high level of fire loading and source of fuel; and b) the immediate aftermath of a tent fire in an informal refugees

The high density in which most refugees live leads to a high risk of rapid fire spread. Beyond that, variations in structure shape fire risk. The points of ignition for fire within informal refugee settlements are similar

\footnotetext{
${ }^{11}$ https://ourworldindata.org/causes-of-death\#fire [Accessed 9/6/2020]
} 
to those found in informal settlements in New Delhi and Cape Town. Open flames or informal electricity connections are used for cooking, heating, and lighting in most settlements because residents are banned from obtaining formal electricity connections In sub-standard buildings, electrical faults are also a risk due to poor quality wiring and connections, enabled by poor dissemination and policing of fire safety regulations. Arguably, sub-standard buildings pose a greater risk of fire fatalities and injuries due to limited means of egress, compared to single level, simply laid out tented settlements (Inter-Agency Coordination Lebanon et al., 2018). In both informal settlements and sub-standard buildings, construction materials such as tarpaulin, wood, plastic, cardboard and rubber tyres to weigh-down roofs may aid the spread of fire (Figure 6). As in New Delhi and Cape Town, seasonal dynamics matter, particularly within informal settlements. Summertime, which is hot, dry and windy in Lebanon, is particularly hazardous. Arson is also a cause of some refugee settlement fires. The wider literature on fires in refugee settlements has highlighted the role of conflict-related arson (e.g. Olsen and Rodriguez, 2004) but in Lebanon fire-setting by children left at home by working parents has also been observed.

Whilst the political and socio-economic position of refugees puts most at a relatively high risk of fire, this risk is not spread evenly across the refugee population. In addition to children, the elderly and people with disabilities are vulnerable due to health, sensory and mobility issues. Women, who are the predominant cooks using open flames on a regular basis, and young males who attempt to fight fires, are at risk too (Inter-Agency Coordination Lebanon et al., 2018). This leads to fire being perceived (within informal settlements at least) as one of the most significant hazards, higher than health and access to education (Inter-Agency Coordination Lebanon et al., 2018).

To combat fire risk and to harmonize risk mitigation interventions across Lebanon, the Inter-Agency Shelter Sector Coordination Working Group produced Guidelines for Fire Prevention, Preparedness and Response [FPPR] (Inter-Agency Coordination Lebanon et al., 2018) in January 2018. This document highlights the low level of fire safety knowledge amongst displaced populations and humanitarian agencies, and outlines the technical and prevention, preparedness, and response measures required to mitigate fire risks in refugee and host communities. Technical responses outlined for informal settlements centre around settlement-level interventions such as fire breaks and community first-responder equipment such as fire extinguishers and beaters located at fire points throughout the settlement.

Other prevention and preparedness activities recommended relate to capacity building within humanitarian staff and awareness raising of fire risk and risk reduction techniques in refugee and host communities. The FPPR also pushed for the training of community-based first responder teams, particularly 
within informal settlements. To date, awareness raising has been gendered, attempting to mirror existing gender roles and norms. For men, community level hazard assessments, evacuation drills, fire break techniques, and training with appropriate equipment to tackle the fires were key components; for women household level hazard assessments of risks (cooking, heating, electricity etc.) and how to use fire extinguishers were the key issues. Awareness raising has also targeted children with key messages about what to do if a fire breaks out, who to call and what to say, evacuation drills and personal fire safety.

\section{Comparative insights and future developments}

Informal settlement fires have deadly implications across the globe. Yet, as these case studies demonstrate, they receive comparably little attention from policy makers. Even statistics for fire-related incidents are, at best, lower bound estimates (Twigg et al., 2017). Not counting people's deaths accurately is symptomatic of the fact that populations within informal settlements often do not 'count' politically: the same marginalisation - politically, economically and socially - that forces people to remain within informal settlements, with increased fire risk, also means that their injury and death are less likely to be recorded and recognised. The marginalisation of informal settlement residents, however, does not mean that fire risk is distributed equally within settlements. Rather, it intersects with factors like gender, age, health and disability. Our case studies demonstrate that the majority of fires within informal settlements are started accidentally. When an ignition occurs, the materials of informal dwellings are usually readily ignitable woods, plastics and cloths that release large amounts of stored energy into a developing fire. A fire can easily spread due to combustible construction materials, the storage of fuel within and around homes, the proximity of adjacent homes and the density of the settlement. The fire either finds a natural barrier and burns itself out, or humans intervene and put it out. The latter requires good access (rare in space-constrained informal settlements), sufficient water supply (which is challenged by urban infrastructure capacities and global warming), proximal response teams, and a means with which the public can easily contact those teams and tell them where they are required.

Fundamentally, provision of accessible, affordable, safety-compliant housing is needed to mitigate fire risks. In the interim, incremental improvements can be made with careful attention paid to the social, political and economic contexts of the communities involved. Community-led risk mapping at local level can be a helpful means of engaging with this contextual picture to help minimise risk and build resilience (Aphaylath et al., 2004; MacGregor et al., 2005; Rahmawati et al., 2016). This can be paired with appropriate training, education and equipment to improve a community's capacity to act as a fire responder (World Health Organization (WHO), 2011; Zweig et al., 2018). Both approaches can help people to effect meaningful change. The danger, however, is that 
such initiatives 'responsibilise' communities and lessen pressure on the state or other governing bodies to change the broader structural picture that pushes people into situations of risk in the first place. These governing bodies must, as a matter of urgency, prioritise the provision of interim services, such as the safe provision of affordable electricity and the wholescale provision of sustainable, formal housing.

\section{Conclusions and final remarks}

Urban areas are increasingly seen as places where economic, social and environmental development can achieve the Sustainable Development Goals (SDG) (Koch and Ahmad, 2018). However, this is threatened by fire hazards and other disasters that can result in loss of life, damage to infrastructure, and the associated costs of rebuilding. SDG 11 aims to "make cities and human settlements inclusive, safe, resilient and sustainable" and to substantially increase the number of cities and human settlements adopting and implementing integrated policies and plans for resilience (UN Habitat, 2015b, 2016).The Sendai Framework for Disaster Risk Reduction 2015-2030 (UNISDR, 2015) aims to substantially reduce global disaster mortality by 2030 through priorities for action which include "Build Back Better" in recovery, rehabilitation and reconstruction. In line with this, the resilience of cities should be strengthened through development of quality infrastructure and spatial planning to reduce vulnerability and risk in informal settlements. This includes the development of infrastructure that is resilient, resource efficient and will reduce the risks and impact of disaster (UN Habitat, 2016).

Urban fires, particularly those in informal and low-income settlements, constitute a significant risk, but are still relatively invisible and neglected in disaster management policy and practice. They are the only major hazard not included as a category in the IFRC's annual World Disaster Reports (IFRC, 2016). This neglect is due in a large part to the lack of accurate, consistent and comprehensive data on fire incidence and causal factors (LMICS generally lack the resources and capacities to create strong datasets that could inform and stimulate more effective action), partly to the lack of formal fire management capabilities and resources, and partly because tackling fire in a comprehensive manner would require a political response from all levels of government, led by community needs and interests.

Any attempts to mitigate fire risk prior to a comprehensive political response that tackles the causes of fire must also be community led. The complex socio-politico-economic landscape of each settlement means solutions that fit one situation cannot necessarily be used in another. Therefore, community involvement is vital to ensure that interventions are appropriate, achievable, and sustainable within the local context. Also vital is the participation of fire services and their roles in both risk management and response to fires, and their active engagement in developing new strategies and working methods for urban fires. 
The challenges posed by urban fires need to be addressed. Effective evidenced-based fire engineering strategies will help increase communities' resilience to urban fire risk, and ultimately help to create sustainable cities. 


\section{References}

Aphaylath, K., Thammanosouth, S., Luangsay, B., Souksakhone, P. and Mixay, V. (2004), Lao Urban Fire Risk Assessment Mapping in Vientiane Capital, Lao.

Bankoff, B., Lubken, U. and Sand, J. (2012), Flammable Cities: Urban Conflagration and the Making of the Modern World, University of Wisconsin Press, Madison, WI.

Bhan, G. (2009), "'This is no longer the city I once knew'. Evictions, the urban poor and the right to the city in millennial Delhi”, Environment and Urbanization, Vol. 21 No. 1, pp. 127-142, DOI:

$10.1177 / 0956247809103009$

Crisp, J. (2015), “Zaatari: A Camp and Not a City”, available at: www.refugeesinternational.org/blog/zaatari-camp-and-not-city (accessed 23 August 2015).

Das, V. and Poole, D. (2004), Antrhopology in the Margins of the State, SAR Press, New Mexico.

Delhi Fire Service (DFS). (2017), Annual Statisitcs.

FPASA. (2018), “SA Fire Loss Statistics 2016”, Fire Protection, Vol. June, pp. 13-28.

Francioli, A.P. (2018), Investigating Energy Usage among Low Income Households and Implications for Fire Risk, Stellenbosch University.

Gibson, L., Engelbrecht, J. and Rush, D. (2019), “Detecting historic informal settlement fires with Sentinel 1 and 2 satellite data - Two case studies in Cape Town", Fire Safety Journal, Vol. 108 No. September 2019, DOI:10.1016/j.firesaf.2019.102828.

Gunter, A. and Massey, R. (2017), "Renting Shacks: Tenancy in the informal housing sector of the Gauteng Province, South Africa", Bulletin of Geography, Vol. 37 No. 37, pp. 25-34, DOI: 10.1515/bog-2017-0022

IFRC. (2016), World Disasters Report 2016. Resilience: Saving Lives Today, Investing for Tomorrow, Disasters, DOI: $10.1037 / \mathrm{e} 569662006-003$.

Inter-Agency Coordination Lebanon, Save the Children, ACTED, Medair, NRC, Lebanese Red Cross, PCPM, et al. (2018), INTER-AGENCY SHELTER SECTOR COORDINATION WORKING GROUP: Guidelines for the Fire Prevention, Preparedness, and Response (FPPR).

Jagnoor, J., Ivers, R., Kumar, R. and Jha, P. (2009), "Fire-related deaths in India: how accurate are the 
estimates?", The Lancet, Vol. 374 No. 9684, p. 117, DOI: 10.1016/S0140-6736(09)61287-3

Kahanji, C., Walls, R.S. and Cicione, A. (2019), "Fire spread analysis for the 2017 Imizamo Yethu informal settlement conflagration in South Africa”, International Journal of Disaster Risk Reduction, Vol. 39, DOI: 10.1016/J.IJDRR.2019.101146

Kazerooni, Y., Gyedu, A., Burnham, G., Nwomeh, B., Charles, A., Mishra, B., Kuah, S.S., et al. (2016), "Fires in refugee and displaced persons settlements: The current situation and opportunities to improve fire prevention and control”, Burns, Vol. 42 No. 5, pp. 1036-1046, DOI: 10.1016/j.burns.2015.11.008

Koch, F. and Ahmad, S. (2018), "How to Measure Progress Towards an Inclusive, Safe, Resilient and Sustainable City? Reflections on Applying the Indicators of Sustainable Development Goal 11 in Germany and India”, in Kabisch, S., Koch, F., Gawel, E., Haases, A., Knapp, S., Krellenberg, K., Nivala, J., et al. (Eds.), Urban Transformations, Springer, pp. 77-90, DOI: 10.1007/978-3-319-59324-1_5

Krishnamoorthy, R.R. and Bailey, C.G. (2009), "Temperature distribution of intumescent coated steel framed connection at elevated temperature.", Nordic Steel '09 Construction Conference, pp. 572-579.

MacGregor, H., Bucher, N., Durham, C., Falcao, M., Morrisey, J., Silverman, I., Smith, H., et al. (2005), "Hazard Profile and Vulnerability Assessment for Informal Settlements: An Imizamo Yethu Case Study with special reference to the Experience of Children", Community Risk Assessment and Action Planning Project, Compendium of Case Studies-Guidance Notes., Cape Town.

National Crime Records Bureau. (2016), Accidental Deaths and Suicides in India 2015, New Delhi.

Olsen, P. and Rodriguez, V. (2004), "Rebels storm refugee camp, killing at least 192”, Chicago Tribune.

Paresi, M., Melchiorri, M., Siragusa, A. and Kemper, T. (2016), Atlas of the Human Planet 2016: Mapping Human Presence on Earth with the Global Human Settlement Layer, DOI: 10.2788/582834.

Pharoah, R. (2009), “Fire Risk in Informal Settlements in Cape Town, South Africa”, in Pelling, M. and Wisner, B. (Eds.), Disaster Risk Reduction - Cases From Urban Africa, Taylor \& Francis, pp. 105-125, DOI: $10.4324 / 9781849771016$

Pluke, M. (2017), “Case study - Imizamo Yethu fire disaster 11 March 2017”, Western Cape Disaster Management Risk Symposium, City of Cape Town.

Quintiere, J. (2016), Principles of Fire Behavior, CRC Press. 
Rahmawati, D., Pamungkas, A., Aulia, B.U., Larasati, K.D., Rahadyan, G.A. and Dito, A.H. (2016), "Participatory Mapping for Urban Fire Risk Reduction in High-density Urban Settlement”, Procedia - Social and Behavioral Sciences, Elsevier B.V., Vol. 227 No. November 2015, pp. 395-401, DOI:

10.1016/j.sbspro.2016.06.091

Sanghavi, P., Bhalla, K. and Das, V. (2009), “Fire-related deaths in India in 2001: a retrospective analysis of data”, The Lancet, Vol. 373 No. 9671, pp. 1282-1288, DOI: 10.1016/S0140-6736(09)60235-X

Satapathy, S. and Walia, A. (2007), “Affected Parents' and Other Stakeholders' Perception of a Fire Disaster Management in India: A Situational Analysis”, Disaster Management and Response, Vol. 5 No. 4, pp. 111-118, DOI: 10.1016/j.dmr.2007.08.002

Schmidt, A. (2003), FMO Thematic Guide: Camps versus Settlements. Forced Migration Online 1990-1996 Sokupa, M. (2012), Re-Blocking of Informal Settlements, SAHF, City of Cape Town.

StatsSA. (2014), Statistical Release Mortality and Causes of Death in South Africa, 2011: Findings from Death Notification, Stats Sa, Pretoria, available at:https://doi.org/Statistical release P0309.3.

StatsSA. (2018), "South Africa - Key Statistics”.

Turner, S. (2006), “Negotiating Authority between UNHCR and 'The People’”, Development and Change, Vol. 37 No. 4, pp. 759-778, DOI: 10.1111/j.1467-7660.2006.00500.x

Turok, I. and Borel-Saladin, J. (2016), "Backyard shacks, informality and the urban housing crisis in South Africa: stopgap or prototype solution?”, Housing Studies, Vol. 31 No. 4, pp. 384-409, DOI: $10.1080 / 02673037.2015 .1091921$

Twigg, J., Christie, N., Haworth, J., Osuteye, E. and Skarlatidou, A. (2017), “Improved methods for fire risk assessment in low-income and informal settlements", International Journal of Environmental Research and Public Health, Vol. 14 No. 2, DOI: 10.3390/ijerph14020139.

UN. (2018), 2018 Revision of World Urbanisation Prospects., available at: https://www.un.org/development/desa/publications/2018-revision-of-world-urbanization-prospects. html.

UN Habitat. (2015a), “Habitat III Issue Papers 22-Informal Settlements”, Vol. 2015 No. May, pp. 1-10.

UN Habitat. (2015b), Sustainable Development Goal 11, available at: https://sustainabledevelopment.un.org/sdg11. 
UN Habitat. (2016), HABITAT III New Urban Agenda.

UNHCR. (2011), UNHCR Global Trends 2010.

UNHCR. (2016), Regional Refugee \& Resilience Plan 2017-2018; In Response to the Syria Crisis, DOI: $0.1177 / 009365027900600102$.

UNISDR. (2015), “Sendai Framework for Disaster Risk Reduction”.

Walls, R., Olivier, G. and Eksteen, R. (2017), “Informal settlement fires in South Africa: Fire engineering overview and full-scale tests on 'shacks”, Fire Safety Journal, Elsevier Ltd, Vol. 91 No. March, pp. 997-1006, DOI: 10.1016/j.firesaf.2017.03.061

WHO. (2018), “Global Health Estimates 2016: Estimated deaths by cause and region, 2000-2016”, Disease Burden and Mortality Estimates: CAUSE-SPECIFIC MORTALITY, 2000-2016, available at: https://www.who.int/healthinfo/global_burden_disease/estimates/en/(accessed 13 March 2019). World Health Organization (WHO). (2011), Burn Prevention: Success Stories, Lessons Learned. Zelkowitz, A., Khattar, G.R. and Doherty, M. (2017), Fire Risk Reduction Assessment of Vulnerable Displaced Syrian Populations and Host Communities In Lebanon.

Zweig, P., Pharoah, R., Eksteen, R. and Walls, R.S. (2018), Installation of Smoke Alarms in an Informal Settlement Community in Cape Town, South Africa - Final Report, Cape Town, available at: https://www.westerncape.gov.za/sites/www.westerncape.gov.za/files/smoke_alarm_project_report_ dld_web.pdf. 